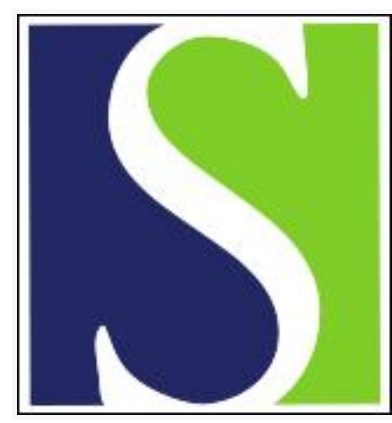

Scand J Work Environ Health 1978;4(3):255-261

https://doi.org/10.5271/sjweh.2709

Issue date: Sep 1978

Effect of occupational exposure to organophosphorus insecticides on neuromuscular function.

by Stalberg E, Hilton-Brown P, Kolmodin-Hedman B, Holmstedt B, Augustinsson K-B

Key terms: cholinesterase activity; electromyography; neuromuscular function; neuromuscular transmission; neuropathy; occupational exposure; organophosphorus compound; organophosphorus insecticide; pesticide; single fiber elecgtromyography

This article in PubMed: www.ncbi.nlm.nih.gov/pubmed/212825 


\title{
Effect of occupational exposure to organophosphorus insecticides on neuromuscular function
}

\author{
by ERIK STÅLBERG,'1 PER HILTON-BROWN,2 BIRGITTA KOLMODIN- \\ HEDMAN, ${ }^{3}$ BO HOLMSTEDT ${ }^{4}$ and KLAS-BERTIL AUGUSTINSSON ${ }^{5}$
}

\begin{abstract}
STÅLBERG E., HILTON-BROWN, P., KOLMODIN-HEDMAN, B., HOLMSTEDT, B. and AUGUSTINSSON, K.-B. Effect of occupational exposure to organophosphorus insecticides on neuromuscular function. Scand. $j$. work environ. \& health 4 (1978) 255-261. Neurophysiological investigations and determinations of cholinesterase activity on plasma and erythrocytes were carried out on 11 Swedish spraymen exposed to bromophos, diazinon, dursbane, and malathion. Plasma cholinesterase activity was significantly reduced after work, while erythrocyte cholinesterase activity was unchanged. In none of the workers with a decreased plasma cholinesterase activity after work could any related acute neuromuscular disturbance be detected when the men were tested with repetitive nerve stimulation and with single fiber electromyography. Signs of subclinical neuropathy were present as a slight reduction in sensory conduction velocity and increased fiber density in some workers.
\end{abstract}

Key words: cholinesterase activity, electromyography, neuromuscular transmission, neuropathy, organophosphorus compounds, pesticides, single fiber electromyography.

Electromyography (EMG) has been used on an increasing scale in occupational medicine over the past years $(14,16)$. One example is the study of effects on nerve and muscle in workers handling different kinds of pesticides such as organophos-

1 Department of Clinical Neurophysiology, University Hospital, Uppsala, Sweden.

2 Department of Neurology, University Hospital, Uppsala, Sweden.

3 Department of Occupational Medicine, Karolinska Hospital, Stockholm, Sweden.

4 Department of Toxicology, Swedish Medical Research Council, Karolinska Institute, Stockholm, Sweden.

5 Institute of Biochemistry, University of Stockholm, Stockholm, Sweden.

Reprint requests to: Dr. Erik Stålberg, Department of Clinical Neurophysiology, University Hospital, 75014 Uppsala, Sweden. phorus compounds $(11,15)$. The cholinesterase inhibition of these compounds might possibly affect neuromuscular transmission in exposed workers. Roberts et al. $(11,15)$ suggested that a relatively simple EMG technique was very useful and, to some extent, superior to cholinesterase measurements when the effects of exposure to organophosphorus compounds are being monitored $(6,10,11,15)$.

In the present investigation neuromuscular transmission and cholinesterase activity have been studied with more sensitive methods than were used in earlier investigations. It is an attempt to determine whether a group of Swedish spraymen was exposed to organophosphorus pesticides to such a degree that EMG tests or cholinesterase determinations showed abnormal values and, if so, to correlate the 
methods used. In addition to measuring the decremental response of the surface EMG recording and nerve conduction velocity, we performed single fiber EMG (SFEMG) (17). This method is particularly sensitive to slight neuromuscular disturbances and changes in the terminal innervation pattern. Both plasma and erythrocyte cholinesterase activity was measured.

\section{SUBJECTS AND EXPOSURE}

Eleven men from a company handling the commercial application of insecticides were examined. They were all spraymen, working daily with solutions of $4 \%$ lindane, $0.2 \%$ pyrethrum, $0.125 \%$ pipenonylbutoxide, $2.5 \%$ malathion or $2 \%$ bromophos in kerosene. Intermittently they were exposed to 0.5 diazinon and dursbane. The employment period varied between 1 and 24 years. They were equipped with routine protective devices such as respirators, boots, overalls and gloves. The men were examined clinically, neurophysiologically, and with measurements of blood cholinesterase activity. They also formed their own reference group since measurements were also made after $1-4$ weeks of nonexposure (preexposure values). The measurements following exposure were generally made within $1-24 \mathrm{~h}$ after a period of spraywork. Exposure values were taken during the spring season, and the preexposure values after the summer vacation. Blinod samples for cholinesterase activity analysis were taken immediately before each EMG investigation.

\section{DETERMINATION OF CHOLINESTERASE ACTIVITIES}

The cholinesterase activity of plasma (BuChE) and erythrocytes (AChE) was determined with a gasometric technique using whole blood samples (50 $\mu 1$ applied and dried on filter paper) and butyrylcholine iodide and acetyl- $\beta$-metylcholine iodide as the selective substrates for the two activities $(3,4)$. The activity was expressed in $b_{30}$ vallues, i.e., microliters of carbon dioxide evolved in $30 \mathrm{~min} / 50 \mu \mathrm{l}$ blood. These values can easily be converted to nanomoles of substrate hydrolyzed per second per liter of blood (which is the new unit, called katal, recommended by the International Enzyme Commission) with the following formula:

$$
1 \text { nkat }=0.5 \times b_{30} .
$$

\section{NEUROPHYSIOLOGICAL INVESTIGATIONS}

\section{Nerve conduction studies}

Motor nerve conduction velocity measurements were made with the standard technique with surface recording (metal discs) and stimulating electrodes (DISA, $13 \mathrm{~K} 62$ ). The filter setting of the amplifier was $2 \mathrm{~Hz}$ to $20 \mathrm{kHz}$. The ulnar nerve was stimulated on both sides. The active recording electrode was placed over the belly of the abductor digiti minimi (ADM) muscle and the indifferent electrode over the fifth metacarpophalangeal joint.

Sensory nerve conduction velocity measurements were made from the right sural nerve with antidromic stimulation between the two heads of the gastrocnemius muscle and the recording of the sural nerve action potential at the lateral malleolus with filt pad electrodes (DISA $13 \mathrm{~K} 62$ ).

Furthermore the amplitude of the compound nerve action potential was measured with filt pad electrodes on both sides at the sulcus ulnaris when the ulnar nerve was stimulated at the level of the wrist.

Before all nerve conduction studies we checked that the extremity was warm. The temperature of the laboratory was 
kept constant at $22^{\circ} \mathrm{C}$ in all the investigations.

\section{Muscle response}

The change in the compound muscle action potential was measured from the abductor digiti minimi muscle with repetitive ulnar nerve stimulation. For the recording and stimulating the setting was the same as that used for the measurements of the motor conduction velocity of the ulnar nerve. The amplitude (negative peak) of the first response and the change in amplitude and integrated surface (the whole response) between the first and fourth response at repetitive $2-\mathrm{Hz}$ nerve stimulation (decrement) was measured on-line with a computer (PDP 11/40). The accuracy of the amplitude measurements was $0.1 \mathrm{mV}$. On different occasions the amplitude may vary up to $2 \mathrm{mV}$ (range) in a normal subject. The decrement measurements were made with an accuracy of about $1 \%$, and a value exceeding $5 \%$ (amplitude and surface) was considered abnormal. These parameters were measured at rest and immediately after $20 \mathrm{~s}$ of maximal voluntary activation of the muscle (postactivity facilitation). A final test was made 5 min after the activation period (postactivity exhaustion). Care was taken that the hand muscle was warm during the investigation.

\section{Single fiber electromyography}

SFEMG was performed in the extensor digitorum communis (EDC) muscle and measurements were made of the jitter and fiber density.

Jitter. Jitter recordings were made from the slightly voluntarily activated muscle as previously described (7). The electrode was positioned to record simultaneously activity from two or more muscle fibers belonging to the same mator unit. There is a variability in the time interval between two action potentials from muscle fibers in the same motor unit at consecutive discharges, called the jitter, which is on the order of $5-55 \mu$ s in a normal EDC muscle. This jitter is mainly due to a variability in the neuromuscular transmission time (17). The jitter is increased in cases with disturbed neuromuscular transmission even before impulse blocking occurs, i.e., before decrement studies or clinical tests show any abnormalities. The jitter analysis was made on a computer (PDP 11/40) off-line. Exceptionally manual analysis was made from measurements of recordings on film or a storage oscilloscope. Recordings were made from 10-20 potential pairs (corresponding to $20-40$ motor end-plates) at each investigation.

Fiber density. Fiber density is the average number of muscle fibers from one mator unit within the SFEMG electrode uptalke area (radius about $270 \mu \mathrm{m}$ ), abtained from 20 recording sites. The method and normal results for different ages have been presented earlier (18).

In case of reinnervation (posttraumatic, polyneuropathy, etc.) the organization of muscle fibers in the motor unit is changed, due to collateral sprouting, and causes an increased fiber density.

Statistical methods. Student's t-test of paired differences with the one-tailed test was used for the statistical analysis.

\section{RESULTS}

\section{Clinical investigation}

None of the examined subjects reported clinical symptoms of intoxication indicating a reaction to organophosphate exposure. Apart from occasional headache, sometimes related to work, the subjects had no symptoms or signs of any neurological disturbance.

\section{Cholinesterase activities}

The cholinesterase activities of the 11 spraymen before and the mean difference between the values after and before exposure are presented in table 1 . The values 
Table 1. Cholinesterase values and neurophysiological data.

\begin{tabular}{|c|c|c|c|c|c|c|}
\hline \multirow{2}{*}{ Variable } & & \multicolumn{2}{|c|}{$\begin{array}{l}\text { Preexposure } \\
\text { value }\end{array}$} & \multicolumn{2}{|c|}{$\begin{array}{l}\text { Difference between pre- } \\
\text { and postexposure values }\end{array}$} & \multirow{2}{*}{$p$ values } \\
\hline & & Mean & SD & Mean & $\mathrm{SD}$ & \\
\hline $\begin{array}{l}\text { Erythrocyte cholin- } \\
\text { esterase (AChE) }\end{array}$ & $\left(\mathrm{b}_{30}\right)$ & 33.3 & 1.8 & -2.04 & 8.8 & $\mathrm{p}>0.2$ \\
\hline $\begin{array}{l}\text { Plasma cholin- } \\
\text { esterase (BuChE) }\end{array}$ & $\left(b_{30}\right)$ & 77.6 & 8.7 & -6.14 & , 6.3 & $\mathrm{p}<0.01$ \\
\hline $\begin{array}{l}\text { Motor conduction } \\
\text { velocity }\end{array}$ & $(\mathrm{m} / \mathrm{s})$ & 58.6 & 5.3 & 1.6 & 4.0 & $\mathrm{p}>0.1$ \\
\hline $\begin{array}{l}\text { Sensory conduction } \\
\text { velocity }\end{array}$ & $(\mathrm{m} / \mathrm{s})$ & 42.4 & 3.6 & -1.3 & 2.4 & $p=0.05$ \\
\hline $\begin{array}{l}\text { Compound nerve action } \\
\text { potential (mean values } \\
\text { for right and left arm) }\end{array}$ & $(\mu \mathrm{V})$ & 81.6 & 18.2 & -3.6 & 15.1 & $\mathrm{p}>0.2$ \\
\hline Muscle response & $(\mathrm{mV})$ & 10.6 & 1.8 & 1.1 & 1.6 & $\mathrm{p}>0.2$ \\
\hline Fiber density & & 1.6 & 0.2 & 0.04 & 0.2 & $\mathrm{p}>0.2$ \\
\hline Mean jitter & $(\mu \mathrm{s})$ & 29.7 & 7.3 & 1.08 & 5.4 & $\mathrm{p}>0.2$ \\
\hline
\end{tabular}

were all within the normal range reported for the technique used (3). The results revealed that plasma cholinesterase activity was decreased $8 \%$ on the average (range $0-25 \%$ ) after exposure $(p<0.01)$. Only one subject had a decrease in plasma activity exceeding the normal intraindividual variation. In this connection it may be pertinent to report that 10 of the 11 workers had a lower plasma cholinesterase activity after exposure than before. The erythrocyte cholinesterase was not affected $(p>0.2)$.

\section{Nerve conduction studies}

In the nerve conduction studies (table 1) the motor nerve conduotion velocity was above the lower normal limits $(>45.0 \mathrm{~m} / \mathrm{s})$ in all workers, and no significant decrease could be detected between results on the two occasions $(p>0.1)$. The compound nerve action potential, normally showing a great scatter because of technical difficulties, did not show any significant reduction in amplitude $(p>0.2)$. The sensory conduction velocity was slightly reduced $(3 \%)$ after the exposure period $(p=0.05)$; reduction was noted in 7 of the 11 workers.

\section{Muscle response}

No decremental response (table 1) and no postactivity facilitation or exhaustion was observed in any of the workers. The decrement was less than $3 \%$. No signs of repetitive dischanges were found. The recorded compound muscle action potential from the ADM muscle ranged from 7.6 to $14 \mathrm{mV}$ and showed no significant difference before and after the exposure $(p>$ $0.2)$.

\section{Jitter}

Some individual motor end-plates showed an increased jitter before or after exposure (table 1). No consistant difference in the jitter with exposure was found.

\section{Fiber density}

For the group, no difference was seen between pre- and postexposure mean values of the fiber density (table 1). It was unchanged and within normal limits, $1.44 \pm$ 0.15 (18) in seven of the workers (fig. 1). In four cases the fiber density exceeded normal values by 2 SD before exposure. Two had increased fiber density on both the test occasions. 
There was no correlation between cholinesterase activities in plasma or red cells and the neurophysiological parameters (conduction velocities, mean jitter value, number of recordings with increased jitter, fiber density). Neither was there any correlation between changes in cholinesterase activity and changes in the neurophysiological parameters.

\section{DISCUSSION}

This investigation was performed to determine any disturbance in neuromuscular function and possible correlation with a decrease in cholinesterase activity in connection with work with organophosphorus compounds. Earlier reports (11) have indicated that neurophysiological methods could reveal such disturbances even when blood cholinesterase activity was normal. The EMG surface response was said to show a decrement at repetitive nerve stimulation, a decrease after muscle activity, and a lower amplitude after exposure to arganophosphorus compounds (11, 15). The two first findings, and possibly also the third, would indicate disturbed neuromuscular transmission. If this is the case, the decrease in amplitude of the recorded action potential should be proportional to the number of blocked motor end-plates.

Our neurophysiological investigations with surface recordings showed normal response ampilitudes without decrement or postactivity exhaustion. However, these studies can be technically difficult, and there are many possibilities of artifacts giving false positive or possibly negative results (e.g., improper electrode placement, movement of the electrodes during stimulation, change in skin resistance, intramuscular temperature, characteristics of the amplifiers, e.g., filter settings). It is particularly difficult to use the absolute amplitude for comparison between recordings made on different occasions. For the decrement studies it is very important, in situations of minor changes, that changes in both amplitude of the response and its integrated surface be compared. Whether these factors account for some of the abnormal findings reported earlier $(10,11$, 15) cannot be determined since some of the information needed for such an evaluation is missing. In the present study these factors were standardized and kept as constant as possible between the investigations. By means of a computer the measurements were made with a high accuracy.

To detenmine whether any neuromuscular disturbances were present despite our normal surface recordings, we performed SFEMG, which is a sensitive method for the study of the transmission in single motor end-plates in situ and may show abnormalities in muscles having nondecreasing surface responses. In none of the cases did the mean jitter change after a period of work. The investigation thus

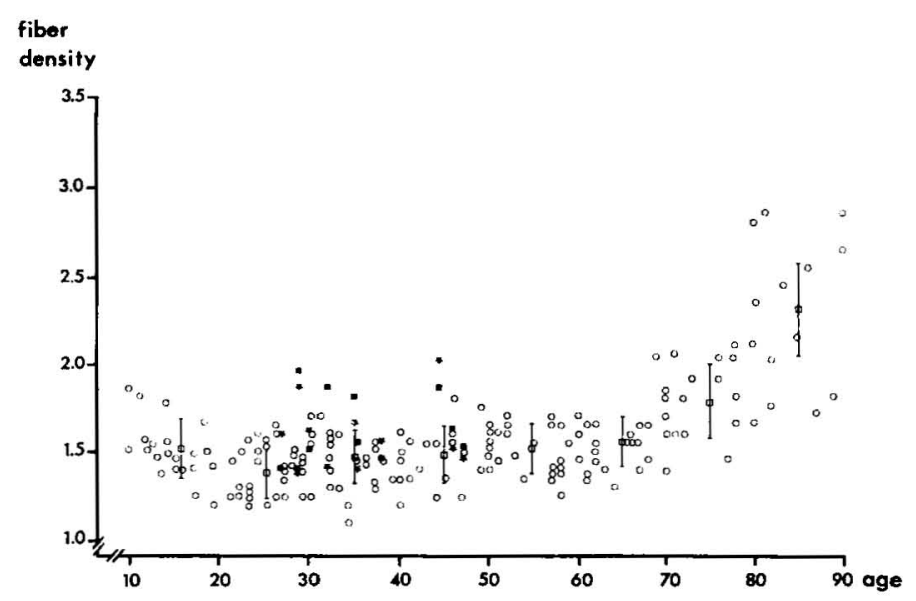

Fig. 1. Fiber density in the extensor digitorum muscle. Open symbols represent normal material (18). Mean value and standard deviation for each decade indicated. Filled symbols represent the spraymen, each

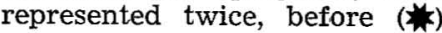
and after ( $\mathbf{n})$ work. 
did not reveal any acutely disturbed neuromuscular transmission. If the surface response shows a low amplitude or decrement due to neuromuscular disturbances, there is always an increased jitter and blockings in the SFEMG recordings.

The slight changes in plasma cholinesterase activity were not correlated to disturbed neuromuscular transmission in the subjects.

In our study we found lower sensory nerve conduction velocities after work in seven subjects. The average reduction for the group was very small $(3 \%)$ but statistically significant $(p=0.05)$. Reduced conduction velocity is usually a sign of neuropathy, which thus may be present in some of our workers. The increase in fiber density in four subjects is interpreted as a sign of peripheral reinnervation after denervation. Such a lesion would most likely be peripherally localized since the mator nerve conduction velocities and compound nerve action potential amplitudes were normal.

The increased jitter values seen in some recordings most likely indicates an uncertain impulse transmission in reinnervation structures [nerve sprouts, immature motor end-plates (9)] but does not relate to acute exposure. A preceding denervation due to neuropathy is a possible explanation.

Certain fluoro-organophosphorus compounds are known to cause delayed neurotoxicity $(1,2,5,12,13)$. Hexane $(20)$ and other hydrocarbon solvents (8) may also cause polyneuropathy.

Verberk and Salle (19) administered mevinphos to volunteers and found a red blood cell cholinesterase depression of $19 \%$. In these men a $7 \%$ decrease in slowfiber motor nerve conduction velocity was found, but the authors stated that this finding might not be found for other organophosphorus compounds.

A peripheral neuropathy could cause a reduced surface action potential, e.g., due to reduced exitability (demyelination) or axonal degeneration. Whether such a reduction explains the lowered amplitude in exposed pesticide workers, reported by others, could not be further tested in our material since the amplitudes did not show any definite changes.

The slight neurophysiological abnormal- ities found in this investigation were unrelated to a lowered cholinesterase activity.

\section{ACKNOWLEDGMENTS}

The study was supported by the Swedish Medical Research Council, grant 135 (ES, PH-B).

Professor Åke Swensson, Department of Occupational Medicine, Karolinska Hospital, is thanked for his valuable contribution to the discussion of this paper.

\section{REFERENCES}

1. ALDRIDGE, W. N., BARES, J. M. and JOHNSON, M. K. Studies on delayed neurotoxicity produced by some organophosphorus compounds. Ann. n.y. acad. sci. 160 (1969) $314-322$.

2. ALDRIDGE, W. N. and JOHNSON, M. K. Side effects of organophosphorus compounds: Delayed neurotoxicity. Bull. W. H. O. 44 (1971) 259-263.

3. AUGUSTINSSON, $K$. B. The normaI vaniation of human blood cholinesterase activity. Acta physiol. scand. 35 (1955) 4052.

4. AUGUSTINSSON, $K$. B. and HOLMSTEDT, B. Determination of cholinesterase in blood samples dried on filter paper and its practical application. Scand. j. clin. lab. invest. 17 (1965) 573-583.

5. CAVANAGH, J. B. Peripheral neuropathy caused by chemical agents. Crit. rev. toxicol. 2 (1973):3, 365-417.

6. DRENTH, H. J., ENSBERG, J. F. G., ROBERTS, D. V. and WILSON, A. Neuromuscular function in agricultural workers using pesticides. Arch. environ. health 25 (1972) 395-398.

7. EKSTEDT, J. and STÅLBERG, E. Single fibre EMG for the study of the microphysiology of the human muscle. New dev. emg \& clin. neurophysiol. 1 (1973) 89-112.

8. GAULTIER, M., RANCUREL, G., PIVA, C. and EFTHYMIOU M. L. Polynevrites et hydrocarbures aliphatigous. Eur. toxicol. 6 (1973): 6, $294-296$.

9. HAKELIUS, L. and STÅLBERG, E. Electromyographical studies of free autogenous muscle transplants in man. Scand. j. plast. reconstr. surg. 8 (1974) 211-219.

10. JAGER, K. W. Organophosphate exposure from industrial usage, electroneuromyo- 
graphy in occupational medical supervision of exposed workers. Paper presented at the E.P.A. seminar on "Pesticide induced delayed neurotoxicity." 19-20 Feb. 1976.

11. JAGER, K. W., ROBERTS, D. V. and WILSON, A. Neuromuscular function in pesticide workers. $\mathrm{Br}$. j. ind. med. 27 (1970) 273.

12. JOHNSSON, M. K. A phosphorylation site in brain and the delayed neurotoxic effects in some organophosphorus compounds. Biochem. j. 111 (1969) 487-495.

13. JOHNSON, M. K. Organophosphorus esters causing delayed neurotoxic effect. Mechanism of action and structure/activity studies. Arch. toxicol. 34 (1975) 259288.

14. KNAVE, B., PERSSON, H., GOLDBERG, M. and WESTERHOLM, P. Long-term exposure to jet fuel: An investigation on occupationally exposed workers with special reference to the nervous system. Scand. $j$. work environ. \& health 3 (1976) 152-164.

15. ROBERTS, D. V. A longitudinal electro- myögraphic study of six men occupationally exposed to organophosphorus compounds. Int. arch. occup. environ. health 38 (1977) $221-229$.

16. SEPPÄLÄINEN, A. M. and HÄRKÖNEN, H. Neurophysiological findings among workers occupationally exposed to styrene. Scand. j. work environ \& health 2 (1976) $140-146$.

17. STÅLBERG, E. and EKSTEDT, J. Single fibre EMG and microphysiology of the motor unit in normal and diseased human muscle. New dev. emg \& clin. neurophysiol. 1 (1973) 113-129.

18. STALBERG E. and THIELE, B. Motor unit fibre density in the extensor digitorum communis muscle. $J$. neurol. neurosurg. psychiatry 38 (1975): 9, 874-880.

19. VERBERK, M. M. and SALLE, H. J. A. Effects on nervous function in volunteers ingesting Mevinphos for one month. Toxicol. appl. pharmacol. 42 (1977) 351-358.

20. YAMAMURA, Y. n-Hexane polyneuropathy. Folia psychiatr. neurol. jpn. 23 (1969): 1, 45-57.

Received for publication: 31 January 1978 